Original Article

\title{
Relationship between the deep flexion of the knee joint and the dynamics of the infrapatellar fat pad after anterior cruciate ligament reconstruction via ultrasonography
}

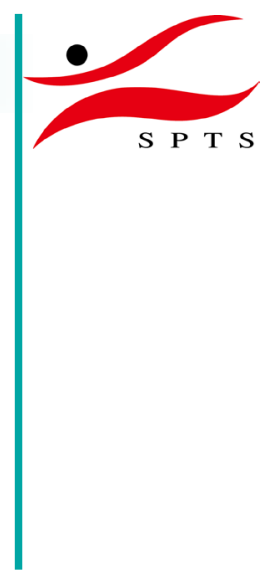

\author{
Takashi Kitagawa, PT, PhD ${ }^{1 *}$, Junsuke Nakase, $\mathrm{MD}, \mathrm{PhD}^{2)}$, Yasushi Takata, $\mathrm{MD}^{2)}$, \\ Kengo Shimozaki, MD²), Kazuki Asai, MD²), Kazu Toyooka, MD²), \\ Hiroyuki Tsuchiya, MD, $\mathrm{PhD}^{2)}$ \\ 1) Department of Physical Therapy, School of Health Sciences, Shinshu University: \\ 3-1-1 Asahi, Matsumoto, Nagano 390-8621, Japan \\ 2) Department of Orthopaedic Surgery, Graduate School of Medical Sciences, \\ Kanazawa University, Japan
}

\begin{abstract}
Purpose] A sufficient flexion angle of the knee joint after knee surgery leads to higher quality of their life; therefore, here we investigated the relationship between the dynamics of the infrapatellar fat pad and seiza-style sitting via ultrasonography. [Participants and Methods] Twenty-eight patients were enrolled 3 months post-operatively after anterior cruciate reconstruction. They were divided into a "possible" group and "impossible" group, according to whether they could sit in the seiza style. The thickness of the superficial part of the infrapatellar fat pad was measured at $10^{\circ}$ and $90^{\circ}$ knee flexion on reconstructed knees in the sitting position via ultrasound evaluation. Images were taken to capture the patella apex and tibial tuberosity. The thickness of the superficial part of the infrapatellar fat pad was measured, and the thickness change ratio was calculated. The characteristics of each group were compared. [Results] The superficial part of the infrapatellar fat pad was significantly thinner in the possible group at a $10^{\circ} \mathrm{knee}$ flexion. The thickness change ratio of the infrapatellar fat pad was significantly greater in the possible group. [Conclusion] The thickness of the infrapatellar fat pad at a $10^{\circ}$ knee flexion and the thickness change ratio of the infrapatellar fat pad could affect the possibility of sitting in the seiza style.

Key words: Anterior cruciate ligament reconstruction, Hoffa's fat pad, Ultrasonography
\end{abstract}

(This article was submitted Mar. 2, 2019, and was accepted Apr. 22, 2019)

\section{INTRODUCTION}

Anterior cruciate ligament (ACL) injury is one of the most common knee injuries, often occurring during sports activities $^{1)}$. The long-term outcome of ACL reconstruction is almost excellent ${ }^{2}$. However, some patients experience a restriction of the range of motion of the knee joint after ACL reconstruction ${ }^{3)}$. Among Japanese people, some have the opportunity to sit on the floor with their knee at full flexion ("seiza") during their activities of daily living (Fig. 1). Clinically, some patients after ACL reconstruction cannot get into the seiza position again, and it decreases their quality of life.

Around the knee joint, there are four fat pads ${ }^{4}$. One of the most important fat pads is the infrapatellar fat pad (IPFP). It has a biomechanical function in the knee joint to decrease the pressure of the patellofemoral joint during knee movement ${ }^{5}$. A previous review about the IPFP noted that the shape of the IPFP changes during knee joint movement ${ }^{6}$.

There are few studies investigating the relationship between the dynamics of IPFP and seiza posture after ACL reconstruc-

*Corresponding author. Takashi Kitagawa (E-mail: kitagawapt@gmail.com)

(C2019 The Society of Physical Therapy Science. Published by IPEC Inc.

(c) (1) $($ This is an open-access article distributed under the terms of the Creative Commons Attribution Non-Commercial No Derivatives

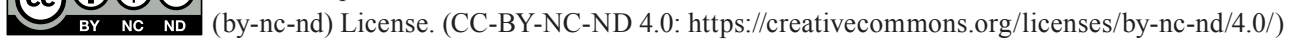



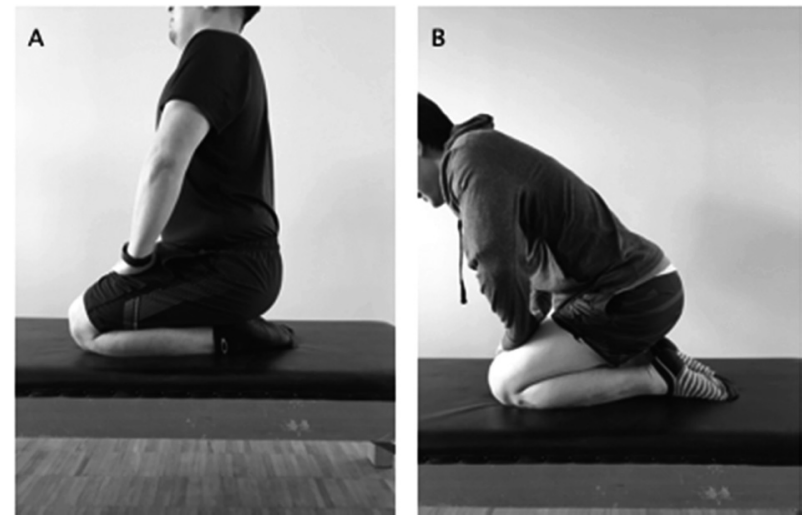

Fig. 1. Seiza style sitting. A: who can sit with seiza style. B: who cannot sit with seiza style.

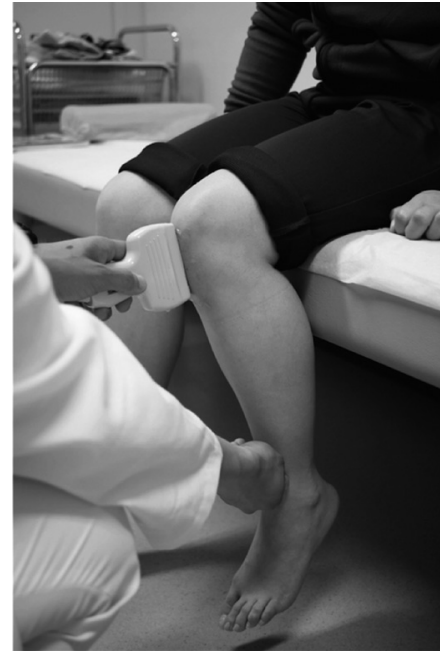

Fig. 2. How to capture the ultrasound image.

tion. The purpose of this study was to investigate the relationship in patients 3 months post-operatively using ultrasonography.

\section{PARTICIPANTS AND METHODS}

Between October 2015 and December 2016, 28 outpatients (mean age; $20.0 \pm 8.1$ years, 12 males and 16 females) provided informed consent to have their knees evaluated using ultrasonography 3 months after ACL reconstruction. Our research protocol conformed to the Declaration of Helsinki. This study was conducted with the approval of the Science and Research Ethics Committee at the Kanazawa University Hospital (approval no. 1929-1). In case of the participant was 20 years old or younger, parental consent was obtained. Inclusion criteria were participant who underwent anatomical single-bundle ACL reconstruction using a hamstring tendon autograft, and who had a full range of motion with their knee joint. Exclusion criteria were participant with bilateral ACL injuries and multiple ACL reconstructions. All reconstructions were performed arthroscopically by one orthopedic surgeon $(\mathrm{JN})$ in our institution. Details of the surgical technique have been published previously ${ }^{7)}$.

For ultrasonographic evaluation, participants were placed in a sitting position. Ultrasound measurements were performed on reconstructed knees with a 5-10-MHz linear transducer (HI VISION Avius, Hitachi Aloka Medical, Tokyo, Japan). Because some patients have difficulty when extensioning their knees actively, the thickness of the superficial part of the IPFP was measured at a $10^{\circ}$ and $90^{\circ}$ knee flexion on reconstructed knees (Fig. 2). The images were taken to capture the patella apex and tibial tuberosity. The IPFP in the images was divided into superficial and deep parts. The thickness of the superficial part of the IPFP was measured using image analysis software, Image J (National Institute of Health, Bethesda, MD, USA) (Fig. 3), according to our established method $^{8}$. The ratio of the change in thickness of the IPFP between the two flexion angles was calculated. Before we acquired the data, the examiner (TK) established between-day inter-tester reliability by evaluating three participants ( $\mathrm{ICC}_{1.1}$ was 0.99 ). Participants were divided into the possible group and the impossible group, according to whether they could sit in the seiza position or not (Fig. 1). For statistical analysis, we used the Mann-Whitney $\mathrm{U}$ test for the univariate analysis of continuous variables between groups. A p-value of less than 0.05 was considered statistically significant.

\section{RESULTS}

Table 1 shows the demographic data of participants. At $90^{\circ}$ knee flexion, there was no significant difference in the thickness of the superficial part of the IPFP between the possible group $(6.8 \pm 4.4 \mathrm{~mm}, \mathrm{n}=12)$ and the impossible group (9.4 \pm $3.8 \mathrm{~mm}, \mathrm{n}=16 ; \mathrm{p}=0.28$ ). At $10^{\circ}$ knee flexion, the superficial part of the IPFP was significantly thinner in the possible group $(3.2 \pm 1.5 \mathrm{~mm})$ than in the impossible group $(5.8 \pm 3.0 \mathrm{~mm} ; \mathrm{p}<0.01)$. The thickness change ratio of the IPFP was significantly greater in the possible group $(234 \pm 129 \%)$ than in the impossible group $(156 \pm 42 \%$; $<0.01)$.

\section{DISCUSSION}

After knee arthroscopy, intra-articular bleeding and effusion might have been caused ${ }^{9}$. Increase of the infrapatellar tissue 


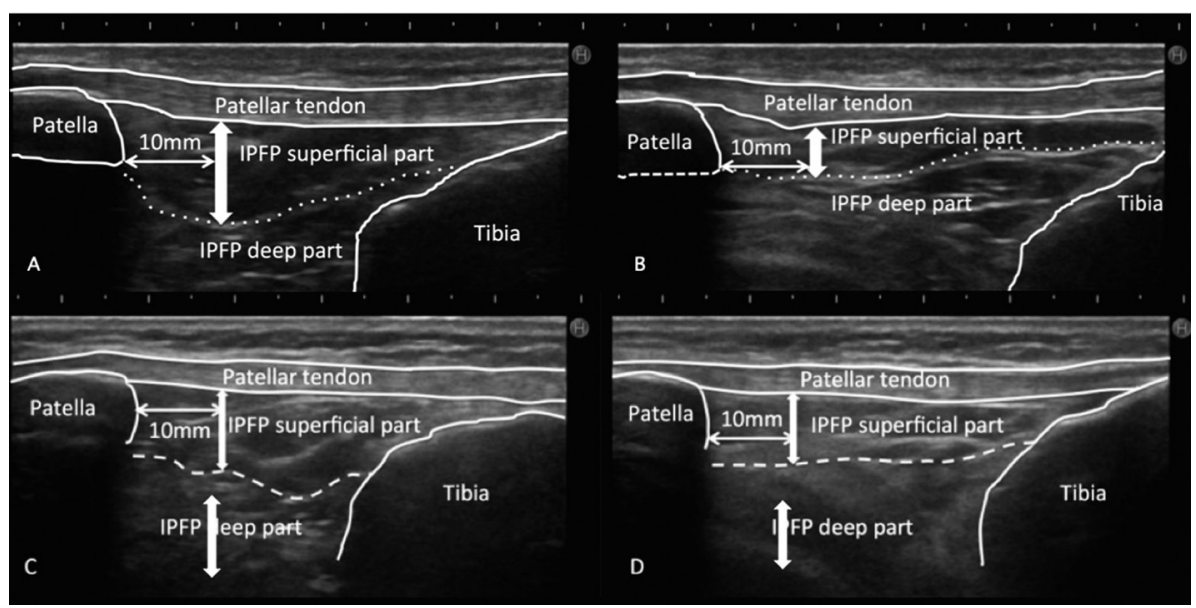

Fig. 3. How to measure the thickness of superficial part of infrapatellar fat pad. The thickness were measured at the flexion of $90^{\circ}(\mathrm{A}, \mathrm{C})$ and $10^{\circ}(\mathrm{B}, \mathrm{D})$. A, B; typical images of the patients who can sit with seiza style. C, D; typical images of the patients who cannot sit with seiza style. IPFP: infrapatellar fat pad.

Table 1. Demographic data of participants

\begin{tabular}{lccc}
\hline & Possible group & Impossible group & p value \\
\hline Gender (male: female) & $4: 8$ & $8: 8$ & 0.38 \\
Age (years) & $19.1 \pm 5.5$ & $22.7 \pm 8.4$ & 0.11 \\
\hline
\end{tabular}

Data indicate mean \pm standard deviation.

during knee flexion, at flexion angles of $<20^{\circ 10}$. In this study, the flexibility of the IPFP might have been preserved after ACL reconstruction in the possible group and it might have kept normal function during knee movement with changing the morphology of the IPFP. While the possibility of seiza sitting style itself might affect the quality of their life, we obtained the ability to investigate the normal knee function recovery after surgery in this study. During arthroscopic surgery of the knee joint, the IPFP is sometimes partially resected in order to expand the surgical field ${ }^{11)}$. Although we could not evaluate the resection volume or the precise site of the IPFP in this study, the superficial part was presumably partially resected, which may have affected the thickness of this part.

One study has reported that fibrosis was observed in the IPFP after arthroscopy ${ }^{12)}$. Another study found that the echo intensity of soft tissue was positively correlated with the ratio of fibrosis tissue ${ }^{13}$. Although this study has not evaluated the echo intensity quantitatively, there was a tendency for the IPFP to have higher echo intensity. There might be a possibility that the IPFP in the impossible group was more fibrotic than the possible group and resulted in a decrease in flexibility of the IPFP. Because the decrease in the flexibility of the IPFP would be related to abnormal kinematics of the patellofemoral or tibiofemoral joint ${ }^{14,15)}$, this will be the restriction factor for seiza posture.

This study has two limitations. First, we could only measure the thickness of the superficial part of the IPFP. Second, we could not evaluate the tissue histopathologically. In conclusion, the thickness of the IPFP in the possible group was thinner than the impossible group at $10^{\circ}$ knee flexion, and the thickness change ratio of the IPFP in the possible group was greater than in the impossible group. These factors would affect the possibility of sitting in the seiza posture.

\section{Funding}

This research did not receive any specific grant from funding agencies in the public, commercial, or not-for-profit sectors.

\section{Conflict of interest}

None.

\section{REFERENCES}

1) Majewski M, Susanne H, Klaus S: Epidemiology of athletic knee injuries: a 10-year study. Knee, 2006, 13: 184-188. [Medline] [CrossRef]

2) Pinczewski LA, Lyman J, Salmon LJ, et al.: A 10-year comparison of anterior cruciate ligament reconstructions with hamstring tendon and patellar tendon autograft: a controlled, prospective trial. Am J Sports Med, 2007, 35: 564-574. [Medline] [CrossRef] 
3) Mayr HO, Weig TG, Plitz W: Arthrofibrosis following ACL reconstruction—reasons and outcome. Arch Orthop Trauma Surg, 2004, 124: 518-522. [Medline] [CrossRef]

4) Clockaerts S, Bastiaansen-Jenniskens YM, Runhaar J, et al.: The infrapatellar fat pad should be considered as an active osteoarthritic joint tissue: a narrative review. Osteoarthritis Cartilage, 2010, 18: 876-882. [Medline] [CrossRef]

5) Dragoo JL, Johnson C, McConnell J: Evaluation and treatment of disorders of the infrapatellar fat pad. Sports Med, 2012, 42: 51-67. [Medline] [CrossRef]

6) Mace J, Bhatti W, Anand S: Infrapatellar fat pad syndrome: a review of anatomy, function, treatment and dynamics. Acta Orthop Belg, 2016, 82: 94-101. [Medline]

7) Nakase J, Toratani T, Kosaka M, et al.: Technique of anatomical single bundle ACL reconstruction with rounded rectangle femoral dilator. Knee, 2016, 23: 91-96. [Medline] [CrossRef]

8) Kitagawa T, Nakase J, Takata Y, et al.: Use of ultrasonography to evaluate the dynamics of the infrapatellar fat pad after anterior cruciate ligament reconstruction: a feasibility study. J Med Ultrason (2001), 2019, 46: 147-151. [Medline] [CrossRef]

9) Alkan K, Unay K, Berkem L, et al.: Suction drainage influence on knee effusion following partial meniscectomy with partial fat pad or synovium resection. Acta Orthop Traumatol Turc, 2011, 45: 221-224. [Medline] [CrossRef]

10) Bohnsack M, Hurschler C, Demirtas $T$, et al.: Infrapatellar fat pad pressure and volume changes of the anterior compartment during knee motion: possible clinical consequences to the anterior knee pain syndrome. Knee Surg Sports Traumatol Arthrosc, 2005, 13: 135-141. [Medline] [CrossRef]

11) Sonnery-Cottet B, Archbold P, Zayni R, et al.: High lateral portal for sparing the infrapatellar fat-pad during ACL reconstruction. Orthop Traumatol Surg Res, 2011, 97: 870-873. [Medline] [CrossRef]

12) Heard BJ, Solbak NM, Chung M, et al.: The infrapatellar fat pad is affected by injury induced inflammation in the rabbit knee: use of dexamethasone to mitigate damage. Inflamm Res, 2016, 65: 459-470. [Medline] [CrossRef]

13) Pillen S, Tak RO, Zwarts MJ, et al.: Skeletal muscle ultrasound: correlation between fibrous tissue and echo intensity. Ultrasound Med Biol, 2009 , 35: 443-446. [Medline] [CrossRef]

14) Bohnsack M, Wilharm A, Hurschler C, et al.: Biomechanical and kinematic influences of a total infrapatellar fat pad resection on the knee. Am J Sports Med, 2004, 32: 1873-1880. [Medline] [CrossRef]

15) Yoon KH, Tak DH, Ko TS, et al.: Association of fibrosis in the infrapatellar fat pad and degenerative cartilage change of patellofemoral joint after anterior cruciate ligament reconstruction. Knee, 2017, 24: 310-318. [Medline] [CrossRef] 